УДК 547.94:834.2

\title{
ЭКОЛОГИЧЕСКИЕ И ВНУТРИВИДОВЫЕ ОСОБЕННОСТИ СОСТАВА И СОДЕРЖАНИЯ АЛКАЛОИДОВ В НАДЗЕМНОЙ ЧАСТИ CHAMAECYTISUS RUTHENICUS (FISCH. EX WOLOSZCZ.) KLASKOVA, ПРОИЗРАСТАЮЩЕГО НА ЮЖНОМ УРАЛЕ
}

\author{
() И.П. Цыпышева ${ }^{1 *}$, Е.Г. Галкин ${ }^{1}$, П.Р. Петрова ${ }^{2}$, А.В. Ковальская ${ }^{1}$, И.П. Байкова ${ }^{1}$, Ф.3. Галин ${ }^{1,2}$, \\ Н.И. Федоров ${ }^{3}$ \\ ${ }^{1}$ Уфримский институт химии РАН, пр. Октября, 71, Уфра, 450054 (Россия), \\ e-mail: tsipisheva@anrb.ru \\ ${ }^{2}$ Башкирский государственный университет, ул. Заки Валиди, 32, Уфа, \\ 450076 (Россия) \\ ${ }^{3}$ Уфимский институт биологии РАН, пр. Октября, 69, Уфра, 450054 (Россия)
}

\begin{abstract}
Методом хромато-масс-спектрометрии определен состав алкалоидов надземной части растений вида Chamaecytisus ruthenicus (Fisch. ex Woloszcz.) Klaskova, произрастающего на Южном Урале: а именно - трех экологических форм разновидности Chamaecytisus ruthenicus var. ruthenicus (лесная форма и две степные - Зилаирского плато и степного Предуралья) и разновидности Ch. ruthenicus var. Syreiszczikowii (разновидность Сырейщикова). Показано, что содержание алкалоидов в стеблях растений этого вида в период цветения в среднем выше, чем в цветах и листьях, и заметно зависит от условий их произрастания. Среди хинолизидиновых алкалоидов трех экологических форм $C h$. ruthenicus var. ruthenicus и разновидности Ch. ruthenicus var. Syreiszczikowii качественно и количественно определены следующие алкалоиды: спартеин, 12- $N$-метилцитизин, формилцитизин, 5,6-дегидролупанин, 17-оксоспартеин, софокарпин, d-лупанин, 17-оксолупанин и пиридиновый алкалоид аммодендрин. Показано, что d-лупанин доминирует практически во всех изученных образцах, кроме стеблей степной предуральской формы Ch. ruthenicus var. ruthenicus и стеблей Ch. ruthenicus var. Syreiszczikowii, в которых основным компонентом является 17-оксоспартеин. Высокое содержание спартеина зафиксировано в стеблях степной формы Ch. ruthenicus var. ruthenicus, собранной в Предуралье. Софокарпин содержится в растениях лесной и степной (предуральская популяция) формах Ch. ruthenicus var. ruthenicus. Алкалоиды $12-N$-метилцитизин и $17-$-оксолупанин обнаружены только в цветах и листьях лесной формы Ch. ruthenicus var. ruthenicus, а 5,6-дегидролупанин - в образцах Ch. ruthenicus var. Syreiszczikowii. Пиридиновый алкалоид аммодендрин найден только в стеблях лесной формы Ch. ruthenicus var. ruthenicus.

Ключевые слова: Chamaecytisus ruthenicus var. ruthenicus, Ch. ruthenicus var. syreiszczikowii, хинолизидиновые алкалоиды, хромато-масс-спектрометрия
\end{abstract}

Цьпьшева Инна Петровна - кандидат химических наук, старший научный сотрудник, e-mail: tsipisheva@anrb.ru

Галкин Евгений Григорьевич - кандидат химических наук, старший научный сотрудник,

e-mail: spectr@anrb.ru

Петрова Полина Радиковна - аспирант, e-mail: tsipisheva@anrb.ru

Ковальская Алена Витальевна - кандидат химических наук, научный сотрудник, e-mail: tsipisheva@anrb.ru Байкова Ирина Петровна - кандидат химических наук, научный сотрудник, e-mail: spectr@anrb.ru

Галин Фанур Зуфарович - доктор химических наук, главный научный сотрудник, e-mail: galinfz@anrb.ru Федоров Николай Иванович - доктор биологических наук, заведующий лабораторией экологии растительных pecypсов, e-mail: fedorov@anrb.ru

\section{Введение}

Ракитник русский (Chamaecytisus ruthenicus) произрастает во всех ботанико-географических районах южно-уральского региона, за исключением наиболее возвышенных частей хребтов Южного Урала и настоящих степей южного Зауралья [1] и имеет два эколого-ценотических оптимума: в петрофитных степных сообществах и в сообществах дубовых и сосновых разреженных травяных лесов, приуроченных как к сухим почвам, так и к почвам с достаточным увлажнением [2].

Недавно нами было показано, что Chamaecytisus ruthenicus (Fish. ex Woloszcz)

\footnotetext{
* Автор, с которым следует вести переписку.
} 
Klaskova, распространенный в средней полосе России, может рассматриваться в качестве потенциального источника хинолизидиновых алкалоидов группы спартеина [3], обладающих высокой биологической активностью [5-8]. Однако в пределах южно-уральской части ареала этот вид имеет две разновидности. Типичная разновидность Ch. ruthenicus var. ruthenicus представлена двумя экологическими формами - лесной с прутевидными побегами до 1,5 м высотой и степной - низкорослой с сильно изогнутыми побегами. Разновидность Сырейщикова - Ch. ruthenicus var. Syreiszczikowii встречается в Республике Башкортостан (РБ) только на песчаных почвах в пойме реки Камы [9].

Целью настоящего исследования является выявление качественных и количественных различий в алкалоидном составе надземной части двух разновидностей Chamaecytisus ruthenicus (Fish. ex Woloszcz) Klaskova, произрастающих на Южном Урале, - Ch. ruthenicus var. ruthenicus, включая три его экологические формы - лесную и две степные (Зилаирское плато и степное Предуралье), и разновидность Сырейщикова Ch. ruthenicus var. Syreiszczikowii.

\section{Экспериментальная часть}

Сбор и подготовка растительного материала. Сбор растительных образцов ракитника русского проводился в 2011 г. в период цветения на четырех пробных площадях. Лесная форма типичной разновидности Ch. ruthenicus var. ruthenicus была собрана в Катав-Ивановском районе Челябинской области в горно-лесной зоне (поселок Меседа), степные формы типичной разновидности ракитника русского на территории РБ в степной зоне Предуралья (деревня Малый Муйнак) и в горно-лесостепной зоне на Зилаирском плато (деревня Верхняя Казарма). Разновидность Сырейщикова собрана в лесостепной зоне РБ в пойме реки Камы (деревня Елановка). На каждой пробной площади у пятидесяти растений отбирали объединенный образец листьев и цветов, а также образец ветвей (прироста прошлого и текущего годов). Видовая принадлежность определена Н.И. Федоровым (УИБ РАН, Уфа). Гербарные образцы Ch. ruthenicus var. ruthenicus и Ch. ruthenicus var. Syreiszczikowii с мест сбора растительного сырья хранятся в гербарии УИБ РАН. Растительный материал высушивали до воздушно-сухого состояния и измельчали до размера частиц 1 мм.

Bыделение суммы алкалоидов. Экстракцию воздушно-сухого сырья проводили водно-ацетоновой смесью (1 : 9) методом настаивания до получения отрицательной пробы с кремневольфрамовой кислотой. Сумму алкалоидов извлекали стандартным методом в виде свободных оснований [10]. Получили восемь проб: I - листья и цветы, II - стебли лесной формы Ch. ruthenicus var. ruthenicus, III - листья и цветы, IV стебли степной зилаирской формы Ch. ruthenicus var. ruthenicus, V - листья и цветы, VI - стебли степной предуральской формы Ch. ruthenicus var. ruthenicus, VII - листья и цветы, VIII - стебли разновидности Ch. ruthenicus var. Syreiszczikowii.

Хромато-масс-спектрометрические исследования. Хромато-масс-спектрограммы регистрировались на масс-спектрометре высокого разрешения Thermo Finnigan MAТ95ХР, метод ионизации - электронный удар $70 \mathrm{eV}$, температура инжектора $250^{\circ} \mathrm{C}$, колонка $\mathrm{HP}-5 \mathrm{MS}, 30$ м $\times 0,25$ мм $\times 0,25$ мкм толщина фазы; режим: начальная температура $120^{\circ} \mathrm{C} 3$ мин, изотерма $250{ }^{\circ} \mathrm{C} 10$ мин.

Компоненты исследуемых смесей идентифицировали по полным масс-спектрам [11], вероятность сходства зарегистрированных и библиотечных спектров $(\mathrm{Q})$ указана в таблице. В качестве «свидетелей» использовали алкалоиды $12-N$-метилцитизин, d-лупанин и спартеин. Относительный индекс удерживания (RRT) d-лупанина принимали за 1,00. Количественный анализ выполняли методом внутренней нормировки по площадям хроматографических пиков без использования корректирующих коэффициентов, содержание алкалоидов приведено в процентах от веса воздушно-сухого сырья (BCC). За 100\% принимали сумму площадей пиков компонентов.

\section{Обсуждение результатов}

Результаты анализа содержания хинолизидиновых алкалоидов в цветах, листьях и стеблях растений двух разновидностей и трех экологических форм ракитника русского Chamaecytisus ruthenicus (Fish. ex Woloszcz) Klaskova, произрастающих на Южном Урале, приведены в таблице. 
Состав и содержание алкалоидов в надземной части растений разновидностей и экологических форм Chamaecytisus ruthenicus (Fisch. ex Woloszcz.) Klaskova, произрастающих на Южном Урале

\begin{tabular}{|c|c|c|c|c|c|c|c|c|c|c|c|}
\hline \multirow{4}{*}{\multicolumn{4}{|c|}{$\begin{array}{c}\text { Разновидности и экологические формы } \\
\text { Chamaecytisus ruthenicus } \\
\text { (Fisch. ex Woloszcz.) Klaskova }\end{array}$}} & \multirow{2}{*}{\multicolumn{6}{|c|}{$\begin{array}{c}\text { Ch. ruthenicus var. ruthenicus } \\
\text { Экологические формы }\end{array}$}} & \multirow{3}{*}{\multicolumn{2}{|c|}{$\begin{array}{l}\text { Ch. ruthenicus } \\
\text { var. } \\
\text { syreiszczikowil }\end{array}$}} \\
\hline & & & & & & & & & & & \\
\hline & & & & \multicolumn{2}{|c|}{ лесная } & \multicolumn{2}{|c|}{$\begin{array}{c}\text { степная } \\
\text { (Зилаирское плато) }\end{array}$} & \multicolumn{2}{|c|}{$\begin{array}{c}\text { степная } \\
\text { (степное Предуралье) }\end{array}$} & & \\
\hline & & & & $\mathrm{I}^{1}$ & $\mathrm{II}^{2}$ & $\mathrm{III}^{1}$ & $\mathrm{IV}^{2}$ & $\mathrm{~V}^{1}$ & $\mathrm{VI}^{2}$ & $\mathrm{VII}^{1}$ & $\mathrm{VIII}^{2}$ \\
\hline \multicolumn{4}{|c|}{ Сумма алкалоидов ${ }^{3}$} & 1,13 & 1,64 & 1,35 & 0,92 & 0,73 & $\mathbf{0 , 8 1}$ & 0,74 & 1,69 \\
\hline Алкалоиды & $\mathrm{RRT}^{4}$ & $\mathrm{M}^{+5}$ & $\mathrm{Q}^{6}$ & \multicolumn{8}{|c|}{ Содержание компонентов ${ }^{3}$} \\
\hline Спартеин & 0,53 & 234,2069 & 92 & 0,05 & 0,38 & 0,09 & 0,12 & 0,09 & 0,26 & 0,06 & 0,37 \\
\hline Аммодендрин & 0,64 & 208,1545 & 87 & - & 0,15 & - & - & - & - & - & - \\
\hline $12-N$-метилцитизин & 0,77 & 204,1292 & 89 & 0,17 & - & - & - & - & - & - & - \\
\hline Формилцитизин & & & & - & - & - & - & - & + & 0,09 & + \\
\hline 5,6-Дегидролупанин & & & & - & - & - & - & - & + & - & 0,04 \\
\hline 17-Оксоспартеин & 0,89 & 248,1845 & 88 & 0,02 & 0,12 & 0,07 & 0,12 & 0,07 & $\mathbf{0 , 2 7}$ & 0,02 & 1,0 \\
\hline Софокарпин & 0,95 & 246,1701 & 78 & 0,05 & 0,15 & - & - & 0,01 & 0,02 & - & - \\
\hline d-Лупанин & 1,00 & 248,1850 & 95 & 0,47 & 0,86 & 0,99 & $\mathbf{0 , 3 5}$ & $\mathbf{0 , 3}$ & 0,17 & $\mathbf{0 , 3 3}$ & 0,02 \\
\hline 17-Оксолупанин & 1,20 & 262,1643 & 85 & 0,02 & - & - & - & - & - & - & - \\
\hline
\end{tabular}

Примечание. ${ }^{1}$ Цветы и листья; ${ }^{2}$ Побеги первого и второго года развития; ${ }^{3}$ В процентах от веса воздушно сухого сырья (BCC); ${ }^{4}$ Относительный индекс удерживания, условия: температура инжектора $250{ }^{\circ} \mathrm{C}$, колонка HP-5MS, $30 \mathrm{M} \times$ 0,25 мм $\times 0,25$ мкм толщина фазы; режим: начальная температура $120{ }^{\circ} \mathrm{C} 3$ мин, изотерма $250{ }^{\circ} \mathrm{C} 10$ мин; ${ }^{5}$ Измеренные точные значения массовых чисел $\mathrm{M}^{+}$удовлетворительно соответствовали вычисленным брутто-составам представленных алкалоидов; ${ }^{6}$ Вероятность сходства зарегистрированных и библиотечных спектров.Хинолизидиновый алкалоид структурной группы матрина - софокарпин содержится только в растениях лесной и степной предуральской форм Ch. ruthenicus var. ruthenicus, его наибольшее содержание $(0,15 \%)$ выявлено в стеблях лесной формы этой разновидности (проба II). 12- $N$-метилцитизин $(0,17 \%)$ содержится только в образце листьев и цветов лесной формы типичной разновидности (проба I), в этой же пробе обнаружен 17 -оксолупанин (0,2\%). Алкалоид 5,6-дегидролупанин в следовых количествах присутствует в стеблях предуральской популяции степной формы Ch. ruthenicus var. ruthenicus и в количестве $0,04 \%$ в стеблях Ch. ruthenicus var. Syreiszczikowii (пробы VI и VIII соответственно), в этих же образцах найдены следовые количества формилцитизина, содержание которого в пробе VII составляет 0,09\%. Пиридиновый алкалоид аммодендрин выявлен только в стеблях лесной формы Ch. ruthenicus var. ruthenicus с содержанием 0,15\% (проба II).

Согласно полученным данным, содержание алкалоидов у растений лесной формы типичной разновидности ракитника русского сравнимо с содержанием алкалоидов в разновидности Сырейщикова - 1,13\% в цветах и листьях (проба I) и 1,64\% в стеблях (проба II) и 0,74\% в цветах и листьях (проба VII) и $1,69 \%$ в стеблях (проба VIII), но выше содержания алкалоидов в надземной части степной экологической формы Предуралья - 0,73 и 0,81\% соответственно для проб V и VI. Необходимо отметить, что содержание алкалоидов в стеблях растений лесной и степной предуральской формы Ch. ruthenicus var. ruthenicus, a также в стеблях разновидности Сырейщикова в 1,5-2 раза выше, чем в листьях и цветах этих растений, что составляет соответственно 1,64, 0,81 и 1,69\% от массы ВСС. Исключение составляет степная экологическая форма Зилаирского плато - так, в пробе III (цветы и листья) содержание алкалоидов повышено и составляет 1,35\%. Как известно, содержание алкалоидов напрямую связано с интенсивностью ростовых процессов в растении [12]. Поэтому можно предположить, что в условиях засухи, в районе Зилаирского плато в 2011 г., рост стеблей Ch. ruthenicus var. ruthenicus тормозился, а интенсивность процессов метаболизма в листья и цветах возрастала, что объясняет наблюдаемое распределение алкалоидов в органах растения (1,35\% в цветах и листьях против $0,92 \%$ в стеблях).

В результате анализа состава суммы алкалоидов в восьми образцах трех экологических форм $C h$. ruthenicus var. ruthenicus и разновидности Сырейщикова Ch. ruthenicus var. Syreiszczikowii (табл.) были идентифицированы следующие мажорные алкалоиды: хинолизидиновые - спартеин, 12- $N$-метилцитизин, 12- $N$-формилцитизин, 5,6-дегидролупанин, 17-оксоспартеин, софокарпин, d-лупанин, 17-оксолупанин и пиридиновый алкалоид аммодендрин. Алкалоидный состав и содержание индивидуальных компонентов зависели от органа растения и заметно отличались для изученных разновидностей и экологических форм ракитника русского. Только три алкалоида - спартеин, 17-оксоспартеин и d-лупанин - были выявлены во всех образцах Ch. ruthenicus var. ruthenicus и Ch. ruthenicus var. Syreiszczikowi. Так, алкалоид d-лупанин доминировал в сумме алкалоидов проб I, II, III, IV, V типичной разновидности ракитника русского (его содержание от 0,3 до 0,99\%), также он является основным компонентом пробы VII (цветы и листья) 
Ch. ruthenicus var. Syreiszczikowi. Высокое содержание 17-оксоспартеин зафиксировано в стеблях предуральской степной формы Ch. ruthenicus var. ruthenicus (проба VI) и в стеблях разновидности Сырейщикова (проба VIII), что ссоставило от 0,27 и 1,0\% соответственно. Содержание спартеина, как было показано нами ранее [4], во всех случаях выше в стеблях (пробы II, IV, VI, VIII), чем в листьях и цветах, и составляет от 0,12 до $0,38 \%$ от веса воздушно-сухого сырья.

Таким образом, показано, что содержание алкалоидов в Ch. ruthenicus var. Syreiszczikowii и в трех экологических форм Ch. ruthenicus var. ruthenicus, произрастающих на Южном Урале, в типичных погодных условиях заметно выше в стеблях растения, а в стрессовых условиях - например, во время засухи, ускорение процессов метаболизма приводит к повышению содержания алкалоидов в листьях и цветах растения. Установлено, что во всех трех экологических формах Ch. ruthenicus var. ruthenicus и в разновидности Ch. ruthenicus var. Syreiszczikowii основными компонентами суммы алкалоидов являются d-лупанин, $17-$ оксоспартеин и спартеин. Высокое содержание в стеблях и цветах с листьями алкалоида d-лупанина характерно для типичной разновидности ракитника русского, листьев и цветов разновидности Сырейщикова, а спартеин и 17-оксоспартеин являются мажорными компонентами стеблей обеих разновидностей ракитника русского - Ch. ruthenicus var. ruthenicus и Ch. ruthenicus var. Syreiszczikowii. Таким образом, эти растения представляют интерес в качестве источников таких хинолизидиновых алкалоидов, как спартеин, $17-$ оксоспартеин и d-лупанин.

\section{Список литературы}

1. Губанов И.А., Киселёва К.В., Новиков В.С., Тихомиров В.Н. Иллюстрированный определитель растений Средней России. М., 2003. Т. 2. 433 с.

2. Жигунова С.Н., Федоров Н.И., Гуркова Я.О., Михайленко О.И. Экология и фитоценотический ареал вида Chamaecytisus ruthenicus (Fisch. ex Woloszcz.) Klaskova на Южном Урале // Научные ведомости БелГУ. 2012. T. 19. №9. С. 9-13.

3. Ц Цыпышева И.П., Галкин Е.Г., Петрова П.Р., Байкова И.П., Галин Ф.З., Федоров Н.И. Сезонная динамика алкалоидов Chamaecytisus ruthenicus, произрастающего на Южном Урале // Химия растительного сырья. 2015. №3. C. 65-69.

4. Orhan I., Naz Q., Kartal M., Tosun F., Sener B., Choudhary M.I. In vitro anticholinesterase activity of various alkaloids // Zeitschrift fuer Naturforschung. 2007. Vol. 62. Pp. 684-688.

5. Bobkiewicz-Kozlowska T., Dworacka M., Kuczynski S., Abramczyk M., Kolanos R., Wysocka W., Garcia Lopez P.M., Winiarska H. Hypoglycemic effect of quinolizidine alkaloids - lupanine and 2-thionosparteine on nondiabetic and streptozotocin-induced diabetic rats // European Journal of Pharmacology. 2007. Vol. 565. Pp. 240-244.

6. Flores-Soto M.E., Banuelos-Pineda J., Orozco-Suarez S., Schliebs R., Beas-Zarate C. Neuronal damage and changes in the expression of muscarinic acetylcholine receptor subtypes in the neonatal rat cerebral cortical upon exposure to sparteine, a quinolizidine alkaloid // International Journal of Developmental Neuroscience. 2006. Vol. 24. Pp. 401-410.

7. Mc-Cawley E.L. Cardioactive Alkaloids // The Alkaloids: Chemistry and Physiology. Academic Press Inc. New York, 1955. Vol. V. Pp. 79-104.

8. Цыпышева И.П., Галкин Е.Г., Федоров Н.И., Оршанская Я.Р., Федорова В.А., Зарубаев В.В. Активность Chamaecytisus ruthenicus (Fabaceae) в отошении вируса гриппа А (H1N1) // Химия растительного сырья. 2016. №2. C. 153-156.

9. Цвелев Н.Н. Ракитник - Chamaecytisus Link // Флора европейской части СССР. Л., 1987. Т. VI. С. 216-225.

10. Минина С.А., Каухова И.Е. Химия и технология фитопрепаратов. М., 2009. 560 с.

11. National Institute of Standards and Thecnology [Электронный ресурc]. URL: http://www.nist.gov

12. Лугманова М.Р., Шендель Г.В., Федоров Н.И., Михайленко О.И. Сезонная динамика содержания свободных аминокислот и суммы алкалоидов в Aconitum septentrionale (Ranunculaceae) и Euonymus verrucosa (Celastraceae) // Растительные ресурсы. 2010. №4. С. 96-103.

Поступило в редакичюю 12 апреля 2016 г.

После переработки 22 ноября 2016 г. 
Tsypysheva I.P. ${ }^{l}$, Galkin E.G. ${ }^{l}$, Petrova P.R. ${ }^{2}$, Koval'skaya A.V. ${ }^{1}$, Baykova I.P. ${ }^{l}$, Galin F.Z..$^{1,2}$, Fedorov N.I. ${ }^{3}$ ECOLOGICAL AND INTRASPECIFIC FEATURES OF ALKALOIDS CONTENT AND COMPOSITION IN THE EPIGEAL PART OF CHAMAECYTISUS RUTHENICUS (FISCH. EX WOLOSZCZ.) KLASKOVA, GROWING IN THE SOUTHERN URAL

${ }^{1}$ Ufa Institute of Chemistry, Russian Academy of Sciences, pr. Oktyabrya, 71, Ufa, 450054 (Russia),

e-mail: tsipisheva@anrb.ru

${ }^{2}$ Bashkir State University, ul. Zaki Validi, 32, Ufa, 450076 (Russia)

${ }^{3}$ Ufa Institute of Biology, Russian Academy of Sciences, pr. Oktyabrya, 69, Ufa, 450054 (Russia)

The content and composition of alkaloids in the epigeal part of two ecological forms of Chamaecytisus ruthenicus var. ruthenicus growing in Southern Ural (the wood form and two steppe - the Zilairsky plateau and Preural steppe) and Ch. ruthenicus var. Syreiszczikowii version were investigated by GC/MS methods. It was shown that the content of total alkaloids in the stems of this specie is higher than in the flowers with leaves and considerably depends on the conditions of growth.

Quinolizidine alkaloids such as sparteine, 12- $N$-metilmethylcytisine, $N$-formylcytisine, 5,6-dehydrolupanine, 17 oksosparteine, sophokarpine, d-lupanine, 17-oksolupanin and pyridine alkaloid ammodendrine were identified among alkaloids of the mention above ecological forms of Ch. ruthenicus var. ruthenicus and Ch. ruthenicus var. Syreiszczikowii. d-Lupanine, 17-oksosparteine and sparteine are the dominating alkaloids of the stems and leaves with flowers of all studied samples. dLupanine is a major alkaloid of stems of a typical version of a Russian broom, and 17-oksosparteine of a Ch. ruthenicus var. Syreiszczikowii. It was shown, that d-lupanine is the major component of all samples except the stems of Preural steppe form of Ch. ruthenicus var. ruthenicus and the stems of Ch. ruthenicus var. Syreiszczikowii. The 17-oxosparteine prevails in two last samples mentioned above. The high maintenance of spparteine is fixed in stems of steppe form of Ch. ruthenicus var. ruthenicus, collected in Preural.

Sophokarpine contains only in the wood form and the Preural steppe population of the typical version Ch. ruthenicus, and the 12- $N$-methylcytisine and 17-oksolupanine are found in the sample of leaves and flowers of the wood form of the Russian broom. 5,6-Dehydrolupanine and $N$-formylcytisine are found in the stems of Ch. ruthenicus var. Syreiszczikowii and in the stems of the Preural population of the steppe form of the typical variety. The pyridine alkaloid ammodendrine is found only in stems of the wood form of the Russian broom. GC/MS.

Keywords: Chamaecytisus ruthenicus var. ruthenicus, Ch. ruthenicus var. Syreiszczikowii, quinolizidine alkaloids,

\section{References}

1. Gubanov I.A., Kiseleva K.V., Novikov V.S., Tikhomirov V.N. Illiustrirovannyi opredelitel' rastenii Srednei Rossii. [Illustrated Manual of the Middle Russia Plants]. Moscow, 2003, vol. 2, 433 p. (in Russ.).

2. Zhigunova S.N., Fedorov N.I., Gurkova Ia.O., Mikhailenko O.I. Nauchnye vedomosti BelGU, 2012, vol. 19, no. 9, pp. 9-13. (in Russ.).

3. Tsypysheva I.P., Galkin E.G., Petrova P.R., Baikova I.P., Galin F.Z., Fedorov N.I. Khimiia rastitel'nogo syr'ia, 2015, no. 3, pp. 65-69. (in Russ.).

4. Orhan I., Naz Q., Kartal M., Tosun F., Sener B., Choudhary M.I. Zeitschrift fuer Naturforschung, 2007, vol. 62, pp. 684-688.

5. Bobkiewicz-Kozlowska T., Dworacka M., Kuczynski S., Abramczyk M., Kolanos R., Wysocka W., Garcia Lopez P.M., Winiarska H. European Journal of Pharmacology, 2007, vol. 565, pp. 240-244.

6. Flores-Soto M.E., Banuelos-Pineda J., Orozco-Suarez S., Schliebs R., Beas-Zarate C. International Journal of Developmental Neuroscience, 2006, vol. 24, pp. 401-410.

7. Mc-Cawley E.L. The Alkaloids: Chemistry and Physiology. Academic Press Inc. New York, 1955, vol. V, pp. 79-104.

8. Tsypysheva I.P., Galkin E.G., Fedorov N.I., Orshanskaia Ia.R., Fedorova V.A., Zarubaev V.V. Khimiia rastitel'nogo syr'ia, 2016, no. 2, pp. 153-156. (in Russ.).

9. Tsvelev N.N. Flora evropeiskoi chasti SSSR. [Flora of the European part of the USSR]. Leningrad, 1987, vol. VI, pp. 216-225. (in Russ.).

10. Minina S.A., Kaukhova I.E. Khimiia i tekhnologiia fitopreparatov. [Chemistry and Technology of herbal remedies]. Moscow, 2009, 560 p. (in Russ.).

11. National Institute of Standards and Thecnology [Electronic resource]. URL: http://www.nist.gov

12. Lugmanova M.R., Shendel' G.V., Fedorov N.I., Mikhailenko O.I. Rastitel'nye resursy, 2010, no. 4, pp. 96-103. (in Russ.).

Received April 12, 2016

Revised November 22, 2016

\footnotetext{
${ }^{*}$ Corresponding author.
} 
